\title{
Thermogravimetric and differential thermogravimetric analysis of effect of areal compositional gradient on combustion kinetics of Mexican extra-heavy crude oil
}

\author{
Carlos A. Avendaño-Salazar ${ }^{1, *}$, Edgar Ramírez-Jaramillo ${ }^{2}$.José L. Mendoza de la Cruz ${ }^{2}$, and A. Albiter ${ }^{2}$ \\ ${ }^{1}$ Programa de Maestría y Doctorado en Ingeniería, Universidad Nacional Autónoma de México Facultad de Ingeniería, \\ Circuito Interior s/n, Coyoacán, 04510 Ciudad de México, México \\ ${ }^{2}$ Instituto Mexicano del Petróleo, Eje Central Lázaro Cárdenas Norte 152, San Bartolo Atepehuacan, \\ 07730 Ciudad de México, México
}

Received: 12 July 2019 / Accepted: 30 March 2020

\begin{abstract}
Numerous studies have contributed to a better understanding of the $i n$-situ combustion process that have allowed to determine the most suitable conditions to carry out this process in reservoirs from volatile to extra-heavy crude oils. One of the elements that alter the behavior of this process is the compositional gradient. In this work, the effects of areal compositional variations in the in-situ combustion of three Mexican extraheavy crude oil samples obtained from the same reservoir and extracted under similar production conditions were studied. Physicochemical, thermal, and kinetics analyses (by means of one non-linear method) were carried out to study the areal compositional variations of the extra-heavy crude oil samples, and their effect on the $i n$-situ combustion of this type of crude oil was also analyzed. Physicochemical characterization includes measurements of viscosity, density, water content, and SARA content. Thermal analyses were performed using three heating rates $\left(5{ }^{\circ} \mathrm{C} / \mathrm{min}, 10^{\circ} \mathrm{C} / \mathrm{min}\right.$, and $\left.15{ }^{\circ} \mathrm{C} / \mathrm{min}\right)$, while kinetic analyses were calculated using Friedman's method.
\end{abstract}

\section{Introduction}

To satisfy the continuously increasing demand for energy, the petroleum industry has gradually turned to extra-heavy crude oil production due to the abundance of these types of resources worldwide. However, the production of this type of crude oil represents an important effort due to high viscosity. In order to increase the production of heavy and extra-heavy crude oils, the in-situ combustion process has been proposed as a suitable solution. This technique involves the injection of an oxidizing gas (air) that, in appropriate conditions, burns the heavier fractions of oil in the reservoir, generating an effect that mobilizes the crude oil and improves the oil properties in the reservoir in-situ, increasing its temperature and thereby reducing its viscosity (Castanier and Brigham, 2003). Therefore, the combustion kinetics is an important parameter for understanding and determining the feasibility of in-situ combustion to produce heavy and extra-heavy crude oils (Fassihi et al., 1984).

\footnotetext{
* Corresponding author: avencarl@unam.mx
}

By supplying heat in the presence of oxygen, three chemical reactions related to crude oil combustion can be observed: distillation, Low-Temperature Oxidation (LTO) and High-Temperature Oxidation (HTO) (Kok and Gul, 2013). The distillation stage produces loss of moisture and volatile hydrocarbons. In the LTO reaction, the combustion of crude oil occurs due to the addition of heat (Ambalae et al., 2006). This process generates the necessary fuel (Goncalves et al., 2001) that enables slow combustion. On the other hand, the HTO reaction exhibits a faster mass loss than LTO due to degradation and alteration of hydrocarbons that allow a sustained combustion process to occur (Kok and Gul, 2013). Even though there are several studies that have contributed to a better understanding of the in-situ combustion process, no previous study has focused on investigating the effect of the areal compositional gradient in the combustion kinetics behavior of Mexican extra-heavy crude oil samples from the same reservoir but with different physicochemical properties.

Hence, to extend the knowledge in this area, the present work analyzes the kinetics of three different extra-heavy crude oil samples from the same reservoir and production interval to determine the feasibility of carrying out in-situ 
combustion and understand how the areal compositional variations affect this process.

\section{Materials and experimental procedures}

Three samples (A, B, and C) of extra-heavy crude oil, from three different wells were analyzed in this work; as mentioned above, all samples were obtained from the same oil reservoir, corresponding to the production interval of the Middle Miocene. The characteristics of each well are given in Table 1 and the location of each well is shown in Figure 1.

Samples A, B, and C were collected, stabilized and homogenized at surface conditions $\left(38^{\circ} \mathrm{C}\right.$ and $\left.15 \mathrm{~kg} / \mathrm{cm}^{2}\right)$. All the experiments were performed in duplicate, to ensure repeatability.

The physicochemical properties measured of the three samples analyzed were density, API gravity, pour point, total water content, viscosity, and SARA analysis. Thermal characterization was performed using ThermoGravimetric Analysis (TGA) and Differential ThermoGravimetric Analysis (DTG). The methods and equipment for physicochemical and thermal characterization are listed in Table 2.

For TGA and DTG experiments, an initial sample mass of $6 \mathrm{mg}$ of extra-heavy crude oil in alumina crucibles with a volume of $70 \mu \mathrm{L}$ was employed with three heating rates of 5 , 10 , and $15{ }^{\circ} \mathrm{C} / \mathrm{min}$ and an $\mathrm{O}_{2}$ flow rate of $40 \mathrm{~mL} / \mathrm{min}$.

\subsection{Kinetics theory}

To determine the kinetics parameters of the extra-heavy crude oil samples, in this work, the Friedman method was used. This method was selected due to previous use by other authors (Gundogar and Kok, 2014; Kok and Gul, 2013; Mothé et al., 2013) to calculate the parameters related to combustion processes in crude oils from different places and with different API gravities (from $11^{\circ}$ API to $35^{\circ} \mathrm{API}$ ), showing that this method is effective to describe the combustion stages of crude oils from different reservoirs, as well as modeling the kinetics for extra heavy crude oils. However, there are few works that discuss the effectiveness of Friedman's method in extra heavy crude oils from the same reservoir, with compositional areal gradients. This issue has not been extensively studied, so the objective of applying this method to the experimental results is to study the efficiency of the method for the treatment of samples with a similar composition but with different physical properties, despite being from the same reservoir, as is the case of the samples reported here.

The Friedman method uses an approximate solution to detect the multiple reaction processes of combustion, using the following equation (Friedman, 2007):

$$
\ln \left(\beta\left(\frac{\mathrm{d} \alpha}{\mathrm{d} T}\right)\right)=\ln (A f(\alpha))-\frac{E}{R T}
$$

where $\beta$ is the heating rate, $A$ is the pre-exponential factor, $f(\alpha)$ is the function of the decomposed mass, $\mathrm{d} \alpha / \mathrm{d} T$ is the reaction conversion rate, $E$ is the activation energy, $R$ is the gas constant, and $T$ is the absolute temperature.
Table 1. Wells characteristics.

\begin{tabular}{lcc}
\hline Well & $\begin{array}{c}\text { True vertical depth } \\
\text { mean sea level (meters) }\end{array}$ & Type of well \\
\hline Well A & 2258 & Directional \\
Well B & 2290 & Vertical \\
Well C & 2300 & Vertical \\
\hline
\end{tabular}

The method, with the respective kinetic analysis, were implemented through a computer program developed by the authors, thus reducing calculation times to obtain the kinetic parameters.

\section{Results and discussion}

\subsection{Physicochemical properties of the extra-heavy crude oil samples}

Density tests were performed for all extra-heavy crude oil samples at atmospheric pressure as function of temperature (Tab. 3). Sample C presented the lowest density, while sample A exhibited the highest value. For all samples, as the temperature increased, the density decreased showing the normal behavior of crude oil density.

The experimental results for API gravity, pour point, sediments (suspended inorganic solids from the reservoir formation), and total water content for all samples showed heterogeneities in their physicochemical properties despite the common origin, as observed in Table 4.

The SARA analysis results for samples A, B, and C are given in Table 5 . From the results, differences of $1 \mathrm{wt} \%$ in Saturates, 2 wt\% in Aromatics, 1 wt\% in Resins, and $2 \mathrm{wt} \%$ in asphaltene content were obtained between samples A and B. However, significant differences were observed for the sample $\mathrm{C}$, with respect to the other two samples, as seen in Table 5 .

A comparison between API gravity, viscosity and its relationship with the SARA analysis, is shown in Figure 2. Sample C, which has the highest values of resins and asphaltenes, is the one that has the lowest API gravity and higher viscosity, so there is a consistent relationship between the composition and physicochemical properties analyzed.

The viscosity variations as a function of the temperature for the three oil samples are given in Table 6 . The results are displayed starting from a temperature of $45^{\circ} \mathrm{C}$ because it is an average temperature of operation in the field. At this temperature, the viscosity of sample $\mathrm{C}$ was three times higher than that of sample A. However, as the temperature increased, the difference in the measured viscosity substantially decreased to approximately two thirds of its original value. The differences in viscosity values in all temperature ranges can be attributed to differences shown in SARA analysis.

Considering that the three samples were collected at similar depth conditions, the differences in the physicochemical properties of the three samples can be explained by the areal variations in composition that extra-heavy 


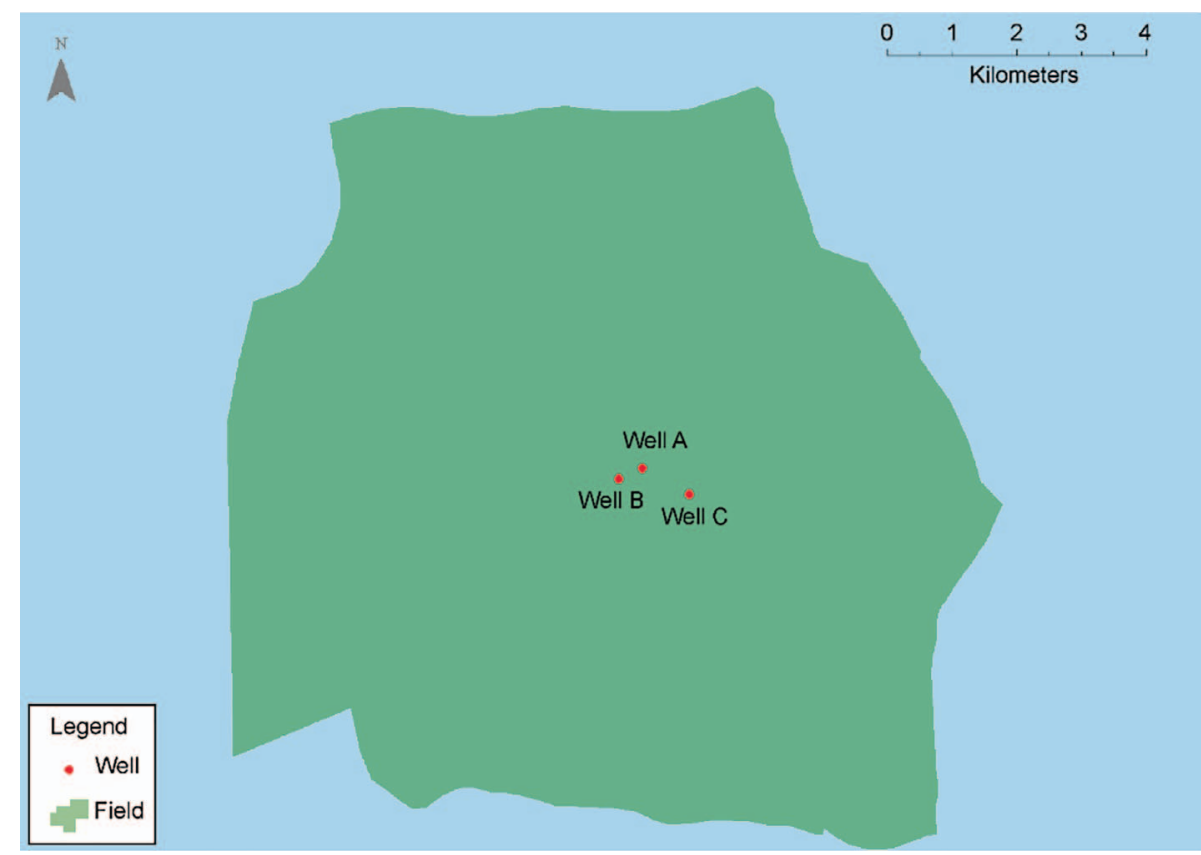

Fig. 1. Locations of wells in the field.

Table 2. Methods and equipment used for physicochemical characterization.

\begin{tabular}{lcc}
\hline Property & Method & Equipment \\
\hline Density & ASTM D5002 & Density meter Anton-Paar ${ }^{\circledR}$ DMA 5000 M \\
API gravity & ASTM D4052 & Density meter Anton-Paar ${ }^{\circledR}$ DMA 5000 M \\
Pour Point & ASTM D5853 & - \\
Total Water Content & ASTM D4006 & Karl Fischer equipment \\
Viscosity & ASTM D7483 & VISCOlab PVT ${ }^{\circledR}$ SPL440 Cambridge Viscosity \\
SARA Analysis & ASTM D2007 & HPLC Waters \\
TGA and DTG & ASTM E1131 & Mettler-Toledo $^{\circledR}$ TGA-DSC 3+ \\
\hline
\end{tabular}

Table 3. Density of the samples studied.

\begin{tabular}{lccc}
\hline $\begin{array}{l}\text { Temperature } \\
\left({ }^{\circ} \mathrm{C}\right)\end{array}$ & $\begin{array}{c}\text { Sample } \\
\mathrm{A}\left(\mathrm{g} / \mathrm{cm}^{3}\right)\end{array}$ & $\begin{array}{c}\text { Sample } \\
\left.\mathrm{B} \mathrm{g} / \mathrm{cm}^{3}\right)\end{array}$ & $\begin{array}{c}\text { Sample } \\
\mathrm{C}\left(\mathrm{g} / \mathrm{cm}^{3}\right)\end{array}$ \\
\hline 20 & 1.004 & 1.011 & 1.014 \\
30 & 0.998 & 1.005 & 1.009 \\
40 & 0.992 & 0.999 & 1.003 \\
50 & 0.986 & 0.993 & 0.997 \\
60 & 0.979 & 0.986 & 0.990 \\
\hline
\end{tabular}

oil reservoirs typically show (Kalehbasti et al., 2011). The compositional variations are mainly caused, but not exclusively, by the distribution and molecular weight of asphaltenes of extra-heavy crude oils (Elshahawi et al., 2007; Weinheber et al., 2012). Considering that properties of paraffins, naphtenes and aromatics may also vary along the reservoir, fluid parameters that depends on the interaction of the SARA fractions for extra-heavy oils can show
Table 4. Physicochemical properties of the samples.

\begin{tabular}{lcccc}
\hline Crude & $\begin{array}{c}\text { API } \\
\text { Gravity }\end{array}$ & $\begin{array}{c}\text { Pour point } \\
\left({ }^{\circ} \mathrm{C}\right)\end{array}$ & $\begin{array}{c}\text { Sediments } \\
(\mathrm{wt} \%)\end{array}$ & $\begin{array}{c}\text { Total water } \\
(\text { vol\%) }\end{array}$ \\
\hline Sample A & 9.15 & 26 & 0.24 & 0.06 \\
Sample B & 8.18 & 23 & 0.25 & 0.93 \\
Sample C & 7.63 & 9 & 0.42 & 0.27 \\
\hline
\end{tabular}

important variations in physicochemical properties (like viscosity), for the same reservoir fluid, within the geological system (Danesh, 1998).

For sample A and sample B, notable differences in the viscosity values were obtained above all the temperature range, despite the similarities found between the values of density (1.004 vs. $1.011 \mathrm{~g} / \mathrm{cm}^{3}$ ) and the SARA analysis (as it was discussed before). These differences in viscosity are caused by the quantity, interaction and stability that exist between the SARA fractions. Little differences of 
Table 5. SARA analysis.

\begin{tabular}{lcccc}
\hline Crude & Saturates (wt\%) & Aromatics (wt\%) & Resins (wt\%) & Asphaltenes (wt\%) \\
\hline Sample A & 10 & 18 & 56 & 16 \\
Sample B & 9 & 16 & 57 & 18 \\
Sample C & 3 & 6 & 70 & 21 \\
\hline
\end{tabular}
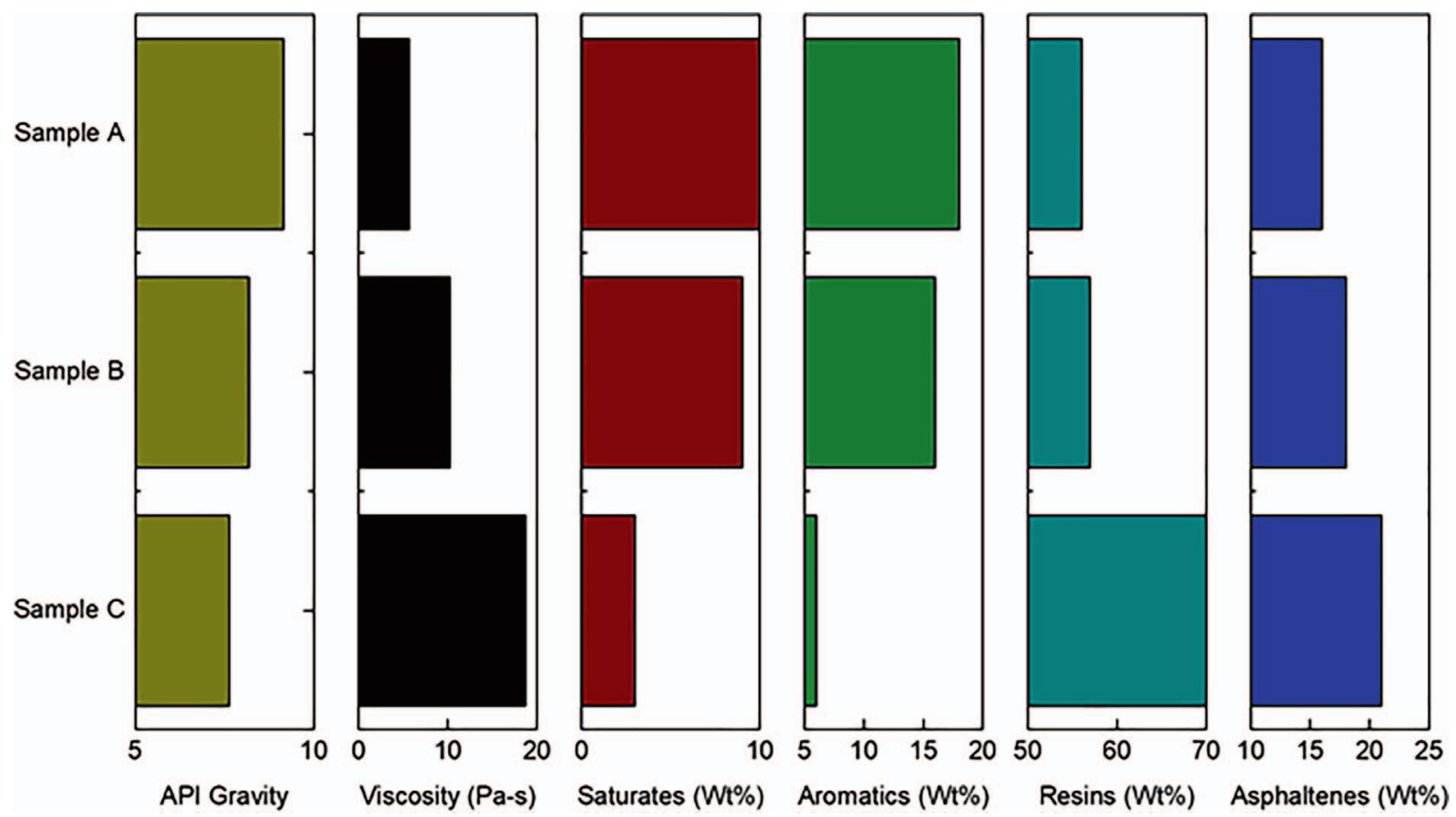

Fig. 2. Comparison of physicochemical properties for samples A, B, and C.

Table 6. Viscosity of crude oil samples.

\begin{tabular}{lccc}
\hline $\begin{array}{l}\text { Temperature } \\
\left({ }^{\circ} \mathrm{C}\right)\end{array}$ & $\begin{array}{c}\text { Sample A } \\
(\mathrm{Pa} \mathrm{s})\end{array}$ & $\begin{array}{c}\text { Sample B } \\
(\mathrm{Pa} \mathrm{s})\end{array}$ & $\begin{array}{c}\text { Sample C } \\
(\mathrm{Pa} \mathrm{s})\end{array}$ \\
\hline 45 & 5.65 & 10.23 & 18.67 \\
50 & 3.52 & 6.14 & 11.32 \\
55 & 2.26 & 3.59 & 6.78 \\
60 & 1.5 & 2.34 & 4.24 \\
65 & 1.03 & 1.57 & 2.73 \\
70 & 0.72 & 1.19 & 1.82 \\
75 & 0.52 & 0.96 & 1.27 \\
80 & 0.38 & 0.65 & 0.88 \\
\hline
\end{tabular}

$1 \mathrm{wt} \%$ in SARA constituents of crude oils can cause differences of almost the double in viscosity values as it has been reported in literature (Peralta-Martínez et al., 2011).

\subsection{Thermal characterization}

The results of TGA/DTG curves of the three extra-heavy crude oil samples at three heating rates of 5,10 , and

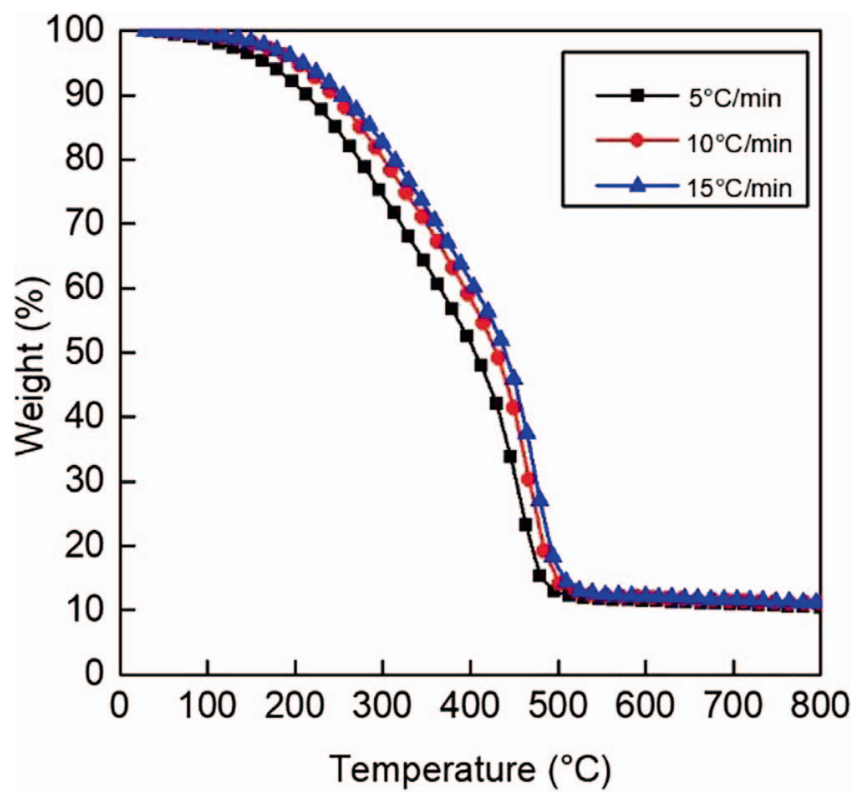

Fig. 3. TGA curves from sample $\mathrm{A}$ at three different heating rates $\left(5,10\right.$, and $\left.15^{\circ} \mathrm{C} / \mathrm{min}\right)$. 


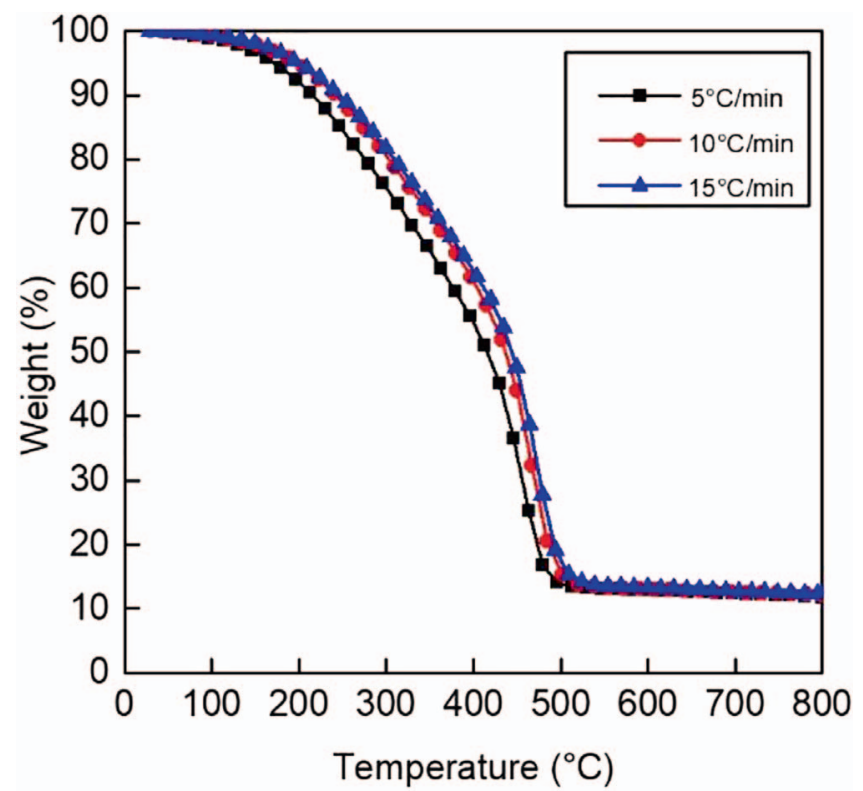

Fig. 4. TGA curves from sample B at three different heating rates $\left(5,10\right.$, and $\left.15^{\circ} \mathrm{C} / \mathrm{min}\right)$.

$15{ }^{\circ} \mathrm{C} / \mathrm{min}$ are shown in Figures $3-5$. The TGA graphs show two reaction regions. Initially, in the first reaction region a distillation process with the first combustion stage (LTO) occurs from $30{ }^{\circ} \mathrm{C}$ to $390{ }^{\circ} \mathrm{C}$ approximately, while in the second reaction region above $390{ }^{\circ} \mathrm{C}$ a $\mathrm{HTO}$ reaction occurs, where the oxidation process is completed.

The respective loss of mass associated with the two reaction regions for samples $\mathrm{A}, \mathrm{B}$, and $\mathrm{C}$ was calculated for all heating rates; it is given in Table 7 .

In the first reaction region, a similar loss of mass compared to the second reaction region was observed; this can be attributed to the combustion of saturated and aromatic compounds (Ali et al., 1998), which correspond to less than $30 \%$ of the weight of these extra-heavy crude oil samples, according to the SARA analysis results. In the second region, the combustion behavior is related to the increase in mass loss of the resins (Kok and Gul,

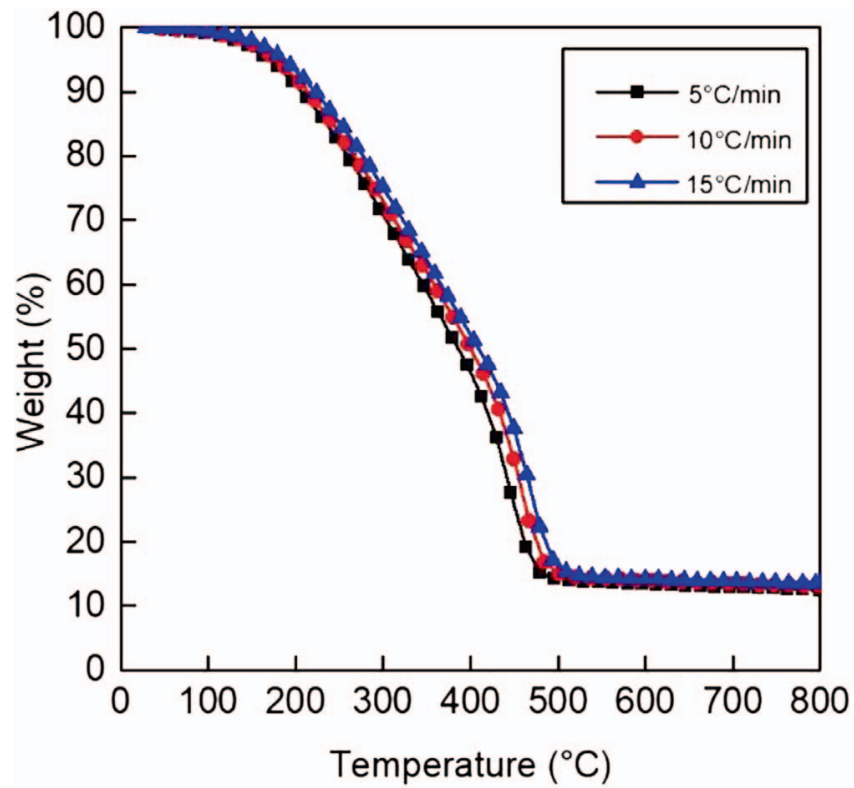

Fig. 5. TGA curves from sample $\mathrm{C}$ at three different heating rates $\left(5,10\right.$, and $\left.15^{\circ} \mathrm{C} / \mathrm{min}\right)$.

2013) and the interaction between resins and asphaltenes (Mothé et al., 2013) as the temperature increases. The integral transformation of the crude oil and the interaction between the components during combustion can explain the similarity observed in the TGA results for samples A, $\mathrm{B}$, and $\mathrm{C}$.

For each of the DTG studies depicted in Figures 6-8, the first reaction region exhibits a gradual mass loss in all samples. This gradual mass loss was identified from the beginning of the experiments and remained stable until a temperature of approximately $380{ }^{\circ} \mathrm{C}$ was reached.

Following the distillation-LTO region, an abrupt increase in the rate of mass loss was observed, as observed in the TGA curves. After the temperature of the samples reached approximately $540{ }^{\circ} \mathrm{C}$, the mass loss stabilized, and a constant rate of mass loss was observed until the end of the experiment at $800{ }^{\circ} \mathrm{C}$.

Table 7. TGA/DTG reaction intervals.

\begin{tabular}{|c|c|c|c|c|c|c|}
\hline \multirow[t]{2}{*}{ Crude } & \multirow{2}{*}{$\begin{array}{c}\text { Heating } \\
\text { rate }\left({ }^{\circ} \mathrm{C} / \mathrm{min}\right)\end{array}$} & \multicolumn{2}{|c|}{ Distillation - LTO } & \multicolumn{2}{|c|}{ HTO } & \multirow{2}{*}{$\begin{array}{l}\text { Total weigh } \\
\text { loss }(\%)\end{array}$} \\
\hline & & Interval $\left({ }^{\circ} \mathrm{C}\right)$ & Weight loss (\%) & Interval $\left({ }^{\circ} \mathrm{C}\right)$ & Weight loss (\%) & \\
\hline \multirow{3}{*}{ Sample A } & 5 & $30-380$ & 43.48 & $380-800$ & 46.05 & 89.53 \\
\hline & 10 & $30-385$ & 38.37 & $385-800$ & 50.64 & 89.01 \\
\hline & 15 & $30-390$ & 36.51 & $390-800$ & 52.35 & 88.86 \\
\hline \multirow{3}{*}{ Sample B } & 5 & $30-370$ & 38.56 & $370-800$ & 49.62 & 88.18 \\
\hline & 10 & $30-375$ & 33.65 & $375-800$ & 54.21 & 87.86 \\
\hline & 15 & $30-380$ & 33.28 & $380-800$ & 54.40 & 87.68 \\
\hline \multirow{3}{*}{ Sample C } & 5 & $30-382$ & 48.89 & $382-800$ & 38.63 & 87.52 \\
\hline & 10 & $30-387$ & 46.70 & $387-800$ & 40.17 & 86.87 \\
\hline & 15 & $30-390$ & 45.49 & $390-800$ & 41.04 & 86.53 \\
\hline
\end{tabular}




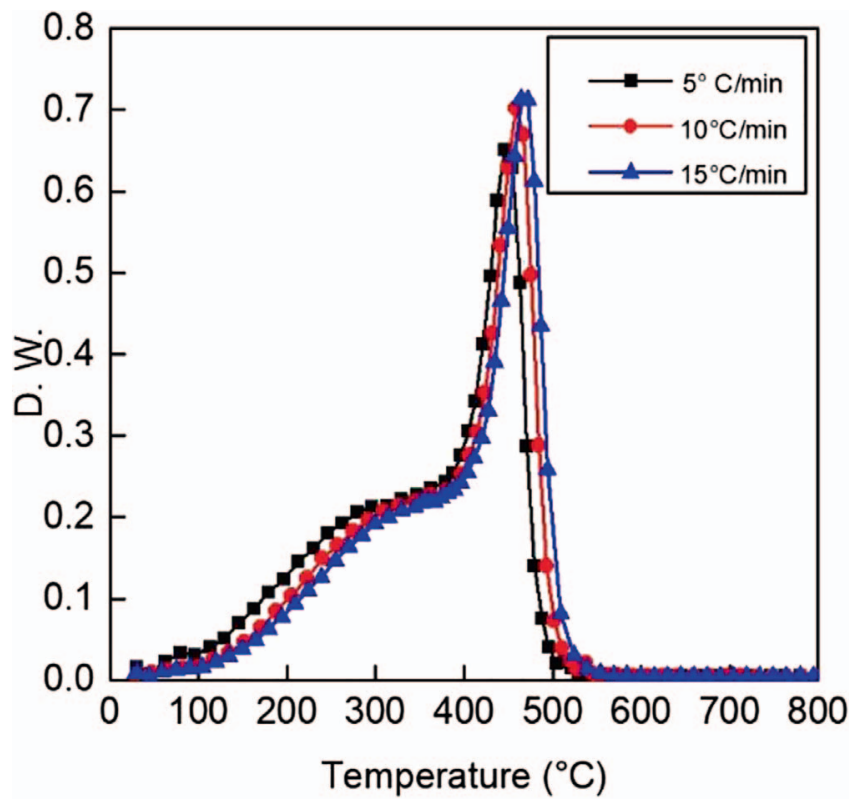

Fig. 6. DTG curves from sample A at three different heating rates $\left(5,10\right.$, and $\left.15^{\circ} \mathrm{C} / \mathrm{min}\right)$.

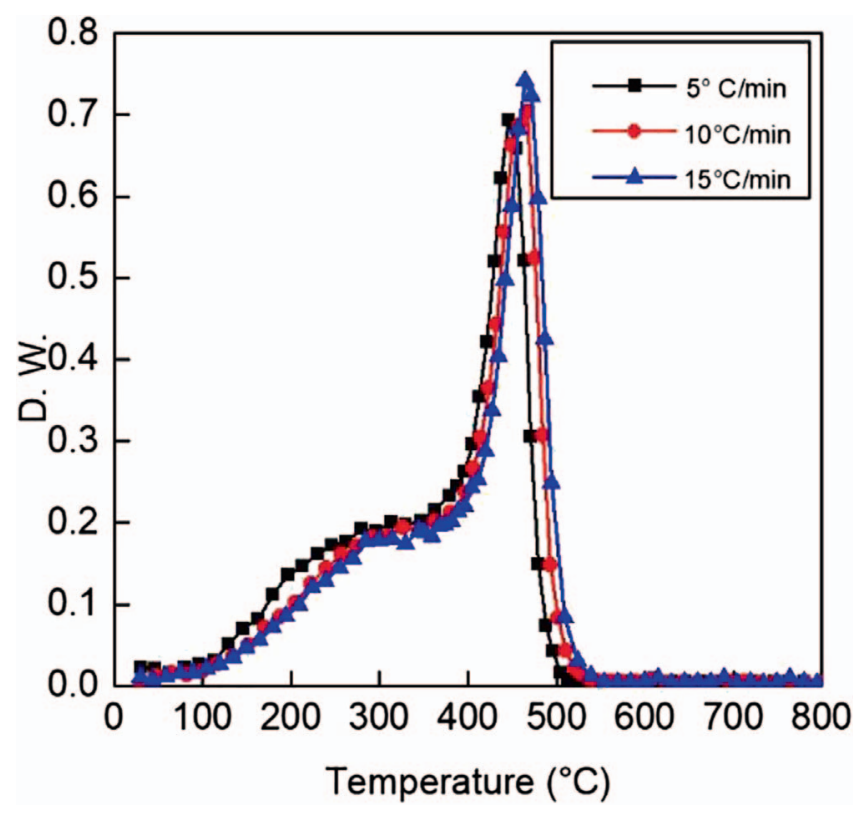

Fig. 7. DTG curves from sample $\mathrm{B}$ at three different heating rates $\left(5,10\right.$, and $\left.15^{\circ} \mathrm{C} / \mathrm{min}\right)$.

\subsection{Kinetic analysis}

The Friedman analysis results for the three samples are presented in Figures 9-11. A single peak can be observed in the three graphs. Sample A exhibits a steeper slope at the beginning of the experimental which could relate the combustion of multiple lighter fractions. Consistent results are obtained with the three methods of analysis used in this study.

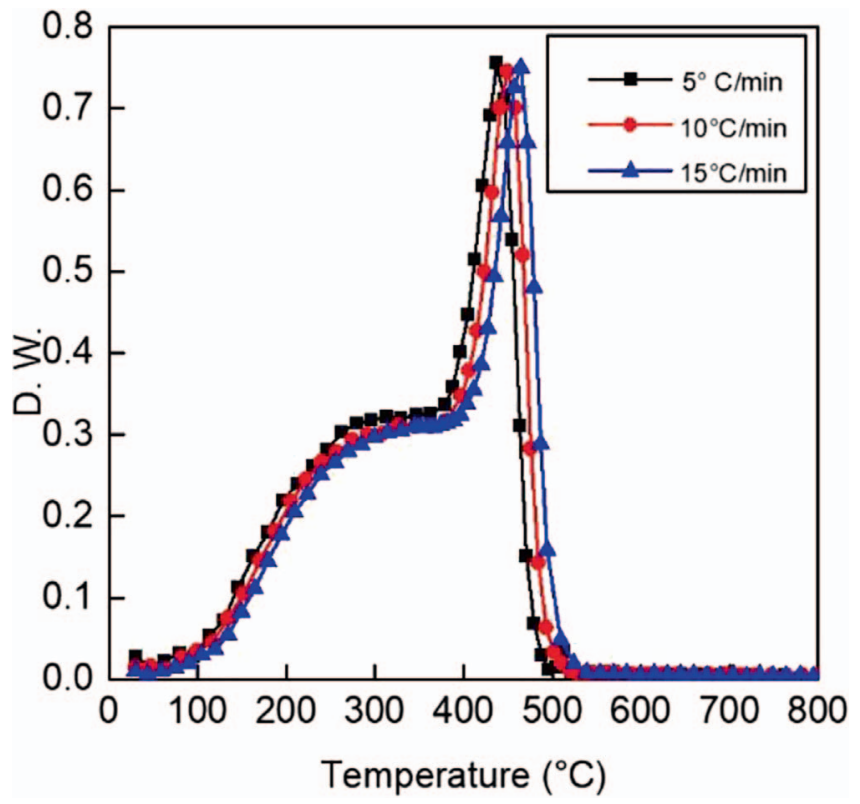

Fig. 8. DTG curves from sample $\mathrm{C}$ at three different heating rates $\left(5,10\right.$, and $\left.15^{\circ} \mathrm{C} / \mathrm{min}\right)$.

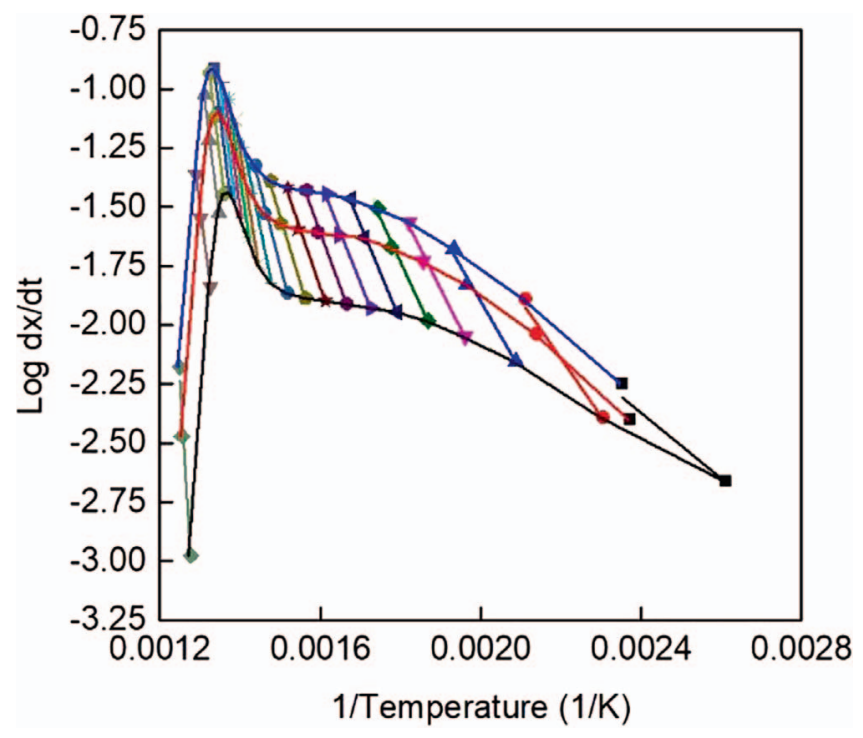

Fig. 9. Isoconversional graph of Friedman's method for sample A.

Kinetic parameters, such as the Activation Energy (Ea) and pre-exponential factor $(A)$, were calculated as a function of the conversion degree $(\alpha)$ for the three samples using the Friedman method. Table 8 summarizes these results: Sample A exhibits the lowest activation energy values for a conversion degree of $0.1-0.5$, while sample $\mathrm{C}$ showed higher activation energy values. This tendency changed for conversion degrees of 0.6-0.9, where Sample B showed the highest activation energy values. An increase in the 


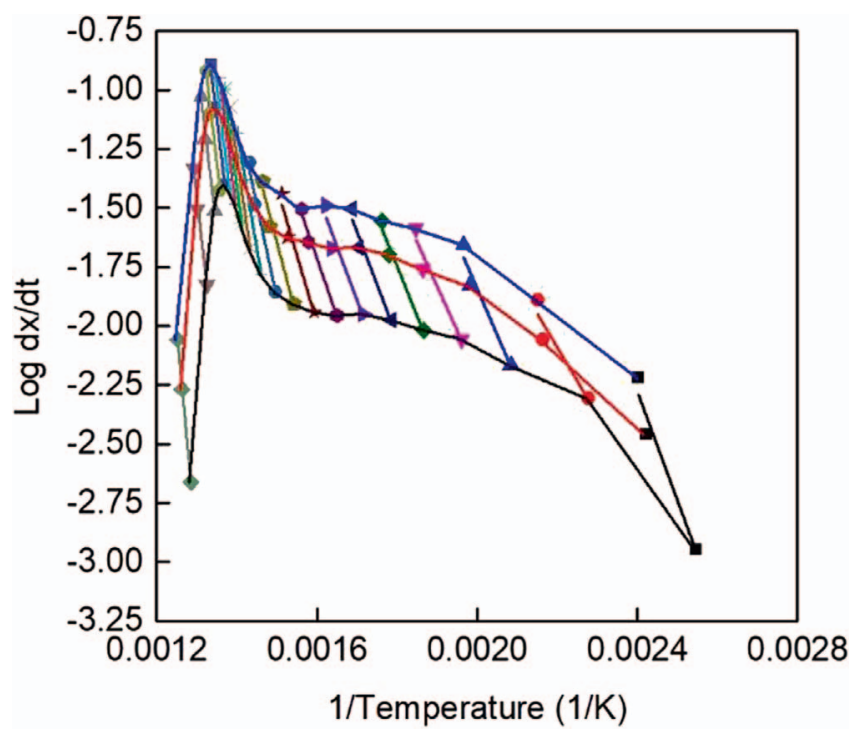

Fig. 10. Isoconversional graph of Friedman's method for sample B.

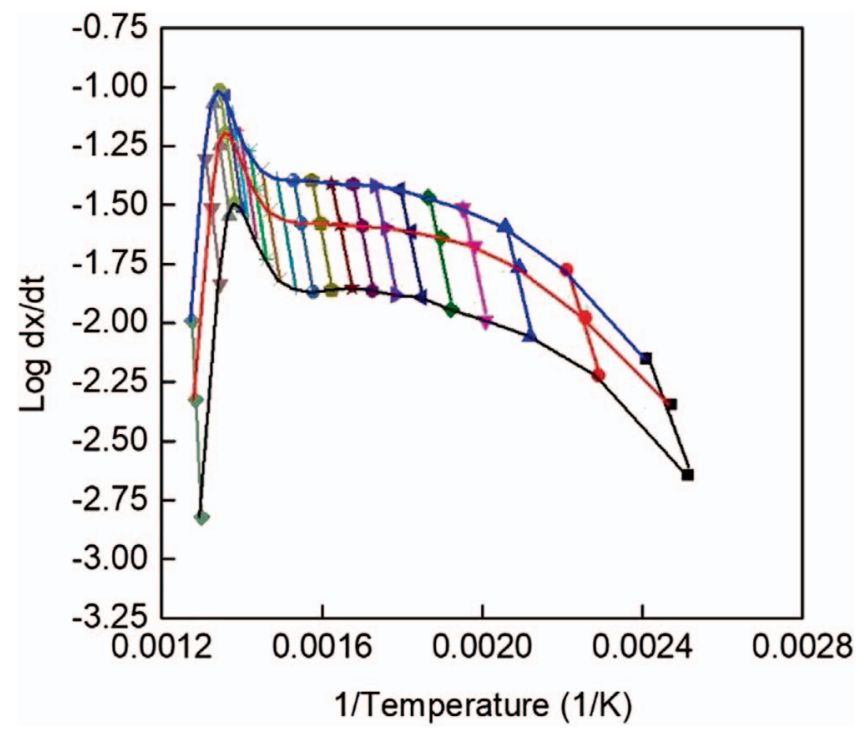

Fig. 11. Isoconversional graph of Friedman's method for sample C.

activation energy values is observed as the degree of conversion increases.

For samples $\mathrm{A}$ and $\mathrm{B}$, the correlation coefficients $\left(R^{2}\right)$ were of 0.99 , indicating that the model is adequate to describe the combustion behavior for the samples. On the other hand, for sample $\mathrm{C}$, the correlation coefficient $\left(R^{2}\right)$ was 0.60 , indicating that the model does not adequately fit the experimental data. The difference in the fit of samples $\mathrm{A}$ and $\mathrm{B}$, with respect to sample $\mathrm{C}$ may be due to the higher viscosity in sample $\mathrm{C}$, which is related to the
Table 8. Calculated activation energy values (Ea) and pre-exponential factors $(A)$ with corresponding conversion degree $(\alpha)$ for Samples A, B and C using Friedman's method.

\begin{tabular}{|c|c|c|c|c|c|c|}
\hline \multirow[t]{2}{*}{$\alpha$} & \multicolumn{2}{|c|}{ Sample A } & \multicolumn{2}{|c|}{ Sample B } & \multicolumn{2}{|c|}{ Sample C } \\
\hline & $\begin{array}{c}\mathrm{Ea} \\
\left(\mathrm{KJ} \mathrm{mol}^{-1}\right)\end{array}$ & $\begin{array}{c}A \\
\left(\mathrm{~s}^{-1}\right) \\
\end{array}$ & $\begin{array}{c}\mathrm{Ea} \\
\left(\mathrm{KJ} \mathrm{mol}^{-1}\right)\end{array}$ & $\begin{array}{c}A \\
\left(\mathrm{~s}^{-1}\right) \\
\end{array}$ & $\begin{array}{c}\mathrm{Ea} \\
\left(\mathrm{KJ} \mathrm{mol}^{-1}\right)\end{array}$ & $\begin{array}{c}A \\
\left(\mathrm{~s}^{-1}\right) \\
\end{array}$ \\
\hline 0.1 & 54.17 & 4.00 & 72.11 & 6.02 & 132.93 & 13.33 \\
\hline 0.2 & 67.65 & 4.90 & 77.42 & 5.85 & 152.24 & 14.03 \\
\hline 0.3 & 78.64 & 5.46 & 83.14 & 5.81 & 162.17 & 13.90 \\
\hline 0.4 & 91.05 & 6.10 & 105.96 & 7.25 & 157.99 & 12.57 \\
\hline 0.5 & 120.99 & 8.14 & 145.14 & 9.98 & 182.24 & 13.80 \\
\hline 0.6 & 192.91 & 13.45 & 216.09 & 15.20 & 191.69 & 13.79 \\
\hline 0.7 & 230.52 & 16.08 & 247.79 & 17.37 & 201.55 & 14.13 \\
\hline 0.8 & 247.47 & 17.09 & 260.28 & 18.02 & 215.16 & 14.90 \\
\hline 0.9 & 251.85 & 16.95 & 261.56 & 17.50 & 224.38 & 15.19 \\
\hline
\end{tabular}

energy needed to carry out the combustion processes in these highly viscous types of oils (Li et al., 2017).

\section{Conclusion}

From the thermogravimetric and differential thermogravimetric analysis studies for samples A, B, and C, two reaction regions of oxidation (distillation-LTO and HTO) were studied, that allowed a similar sustained combustion process with slight differences in terms of the amount of material consumed (for this case, sample A is greatest). The kinetic analysis showed that due to the combustion of multiple lighter fractions, a sustained LTO process was found for all samples that permitted a HTO stage with greater energy release as confirmed by the activation energy results, showing favorable conditions to carry out an in-situ combustion process for these oil samples despite the differences found in the physicochemical characterization.

From the physicochemical results like density, pour point, viscosity, and specially SARA analysis it can be seen differences that mean areal compositional variations in the reservoir. Despite the differences observed between the samples, a similar thermal behavior was observed, which provides information on the way in which these areal variations impact the kinetic behavior. In the future, to determine the feasibility of carrying out the in-situ combustion process, combustion tube experiments should be performed with reservoir crude oil and reservoir sand packs, as a companion of the current experiments.

Acknowledgments. The authors want to acknowledge Universidad Nacional Autónoma de Mexico (UNAM) for the financial support provided, and to the Flow Assurance Laboratory of the Deepwater Technology Center (CTAP) of the Mexican Petroleum Institute (IMP) for allowing the use of its facilities to carry out the present work. 


\section{References}

Ali M.A., Siddiqui M.A.B., Zaidi S.M.J. (1998) Thermal analysis of crude oils and comparison with SIMDIST and TBP distillation data, J. Therm. Anal. Calorim. 51, 1, 307-319. doi: $10.1007 / \mathrm{BF} 02719032$.

Ambalae A., Mahinpey N., Freitag N. (2006) Thermogravimetric studies on pyrolysis and combustion behavior of a heavy oil and its asphaltenes, Energy Fuels 20, 2, 560-565. doi: 10.1021/ef0502812.

Castanier L.M., Brigham W.E. (2003) Upgrading of crude oil via in situ combustion, J. Pet. Sci. Eng. 39, 1-2, 125-136. doi: 10.1016/S0920-4105(03)00044-5.

Danesh A. (1998) PVT and phase behaviour of petroleum reservoir fluids, in: Developments in Petroleum Science, 1st edition, Vol. 47, Elsevier, Amsterdam, The Netherlands.

Elshahawi H., Hows M.P., Dong C., Venkatramanan L., Mullins O.C., McKinney D.E., Flannery M., Hashem M.N. (2007) Integration of geochemical, mud gas and downhole fluid analyses for the assessment of compositional grading - case studies, in: SPE Annual Technical Conference and Exhibition, 11-14 November, Anaheim, California, USA, Society of Petroleum Engineers. No. 1938. doi: 10.2118/109684-MS.

Fassihi M.R., Brigham W.E., Ramey H.J. Jr (1984) Reaction kinetics of in-situ combustion: Part 1 - observations, SPE J. 24, 04, 399-407. doi: 10.2118/8907-PA.

Friedman Henry L. (2007) Kinetics of thermal degradation of char-forming plastics from thermogravimetry. Application to a phenolic plastic, J. Polym. Sci. Part C: Polym. Symp. 6, 1, 183-195. doi: 10.1002/polc.5070060121.

Goncalves M.L.A., Teixeira M.A.G., Pereira R.C.L., Mercury R. L.P., Matos J.R. (2001) Contribution of thermal analysis for characterization of asphaltenes from Brazilian crude oil BT - 12th International Congress on Thermal Analysis and
Calorimetry, August 14, 2000 - August 18, 2000, J. Therm. Anal. Calorim. 64, 2, 697-706. doi: 10.1023/A:1011588226768.

Gundogar Asli S., Kok Mustafa V. (2014) Thermal characterization, combustion and kinetics of different origin crude oils, Fuel 123, 59-65. Elsevier Ltd. doi: 10.1016/j.fuel.2014.01.058.

Kalehbasti M.A., Paroodbari J.R., Ravari R.R., Amani M. (2011) Fluid characterization, a case study of a field with compositional gradient, in: SPE Middle East Oil and Gas Show and Conference, MEOS, Proceedings, 25-28 September, Manama, Bahrain 2. doi: 10.1136/acupmed-2012-010251.

Kok Mustafa Versan, Gul Kiymet Gizem (2013) Thermal characteristics and kinetics of crude oils and SARA fractions, Thermochim. Acta 569, 66-70. Elsevier B.V. doi: 10.1016/j. tca.2013.07.014.

Li Y.B., Chen Y.F., Pu W.F., Dong H., Gao H., Jin F.Y., Wei B. (2017) Low temperature oxidation characteristics analysis of ultra-heavy oil by thermal methods, J. Ind. Eng. Chem. 48, 2016, 249-258. doi: 10.1016/j.jiec.2017.01.017.

Mothé M.G., Carvalho C.H.M., Sérvulo E.F.C., Mothé C.G. (2013) Kinetic study of heavy crude oils by thermal analysis, J. Therm. Anal. Calorim. 111, 1, 663-668. doi: 10.1007/ s10973-012-2574-1.

Peralta-Martínez M.V., García-Trujillo M.E., Palacios-Lozano E.M., Blass-Amador G. (2011) The effect of SARA fractions on viscosity for five Mexican vacuum residues, Energy Sources Part A Recovery Utilization Env. Effects 33, 920-924. doi: 10.1080/15567030903289825.

Weinheber P., Wicher W., Oshmarin R., Driller A., Tsiklakov A., Zimin S., Zuo J. (2012) Determining reservoir connectivity and compositional grading by mapping asphaltene gradients (Russian), Proceedings of SPE Russian Oil and Gas Exploration and Production Technical Conference and Exhibition, 16-18 October, Moscow, Russia. doi: 10.2118/160590-RU. 